\title{
Immunotoxins for the Treatment of B-Cell Lymphomas
}

\author{
Maria-Ana Ghetie, Victor Ghetie, and Ellen S. Vitetta \\ Cancer Immunobiology Center and Department of Microbiology, \\ University of Texas Southwestern Medical Center at Dallas, \\ Dallas, Texas, U.S.A.
}

\section{INTRODUCTION}

Non-Hodgkin's lymphoma (NHL) encompasses a group of hematologic malignancies of $\mathrm{B}$ and $\mathrm{T}$ cell origin. However, the majority of NHLs are B cell lymphomas and these can further be categorized as indolent or low grade, intermediate grade, and aggressive or high grade (1-3). There are approximately $30,000-50,000$ new cases of B cell lymphoma in the United States each year; a large proportion of diagnosed patients will eventually die of this disease despite conventional chemo- and radiotherapy as well as bone marrow transplantation (in refractory or relapsed NHL).

Since NHLs typically express one or more B cell markers, these markers can be used to target antibody-based cytotoxic agents. Although normal B cells will be destroyed, they are repopulated from stem cells lacking the targeted antigens. Alternatively, since B cell tumors are clonal, the immunoglobulin idiotype can be considered a tumor-specific marker. In mice with human lymphoma xenografts, antibodies conjugated to radionuclides, drugs, or toxins can be curative, particularly when combined with other therapies. These immunoconjugates are highly potent in vitro and in mice. However, because they carry a toxic moiety, their safety profile in humans must be carefully established. In the case of antibody toxin conjugates (immunotoxins, or ITs), these agents have displayed better antilymphoma activity at lower concentrations than did unconjugated antibodies both in vitro

Address correspondence and reprint requests to: Dr. Ellen S. Vitetta, Cancer Immunobiology Center and Department of Microbiology, University of Texas Southwestern Medical Center at Dallas, 5323 Harry Hines Boulevard, Dallas, TX 75235-8576, U.S.A. Tel: 214-648-1200, ext. 1250; Fax: 214-648-1204; e-mail: evitet@mednet.swmed.edu and in vivo. Early trials using ITs in patients have established the safe doses and the side effects, and efficacy must now be established in Phase II and III trials. Clearly, ITs have activity in humans but it remains to be determined whether they will improve the long-term prognosis for patients with NHL.

\section{IMMUNOTOXINS}

Two major antigens on B lymphoma cells have been used as targets; CD 19 and CD22. Antibodies against these two molecules have been conjugated to either ricin toxin (RT) (4) or its deglycosylated A chain (dgRTA) (5-8), or pokeweed antiviral protein (PAP) (9).

\section{dgRTA Containing ITs (Fig. 1)}

CD19 is expressed on all normal B cells from the pre-B cell stage to the plasma cell $(10-12)$, whereas CD22 appears on the mature B cell and disappears about the same time as CD19 on activated cells $(10,11)$. CD19 and CD22 are expressed on greater than $90 \%$ and $60-80 \%$ of $B$ lymphomas, respectively. Both anti-CD19 and anti-CD22 have been conjugated to dgRTA and in the case of RFB4-anti-CD22, the monoclonal antibody (MAb) has been used as both intact IgGs (13) and Fab' (14) fragments. dgRTA is produced by deglycosylating the whole molecule of RT followed by separation of the two chains by size and affinity chromatography $(15,16)$. The removal of the carbohydrate moieties from the RTA avoids the problem of liver entrapment and hepatotoxicity. dgRTA as well as other ribosome inactivating proteins (RIPs) from plants, i.e., PAP, Saporin, etc., are glycosidases that inhibit 


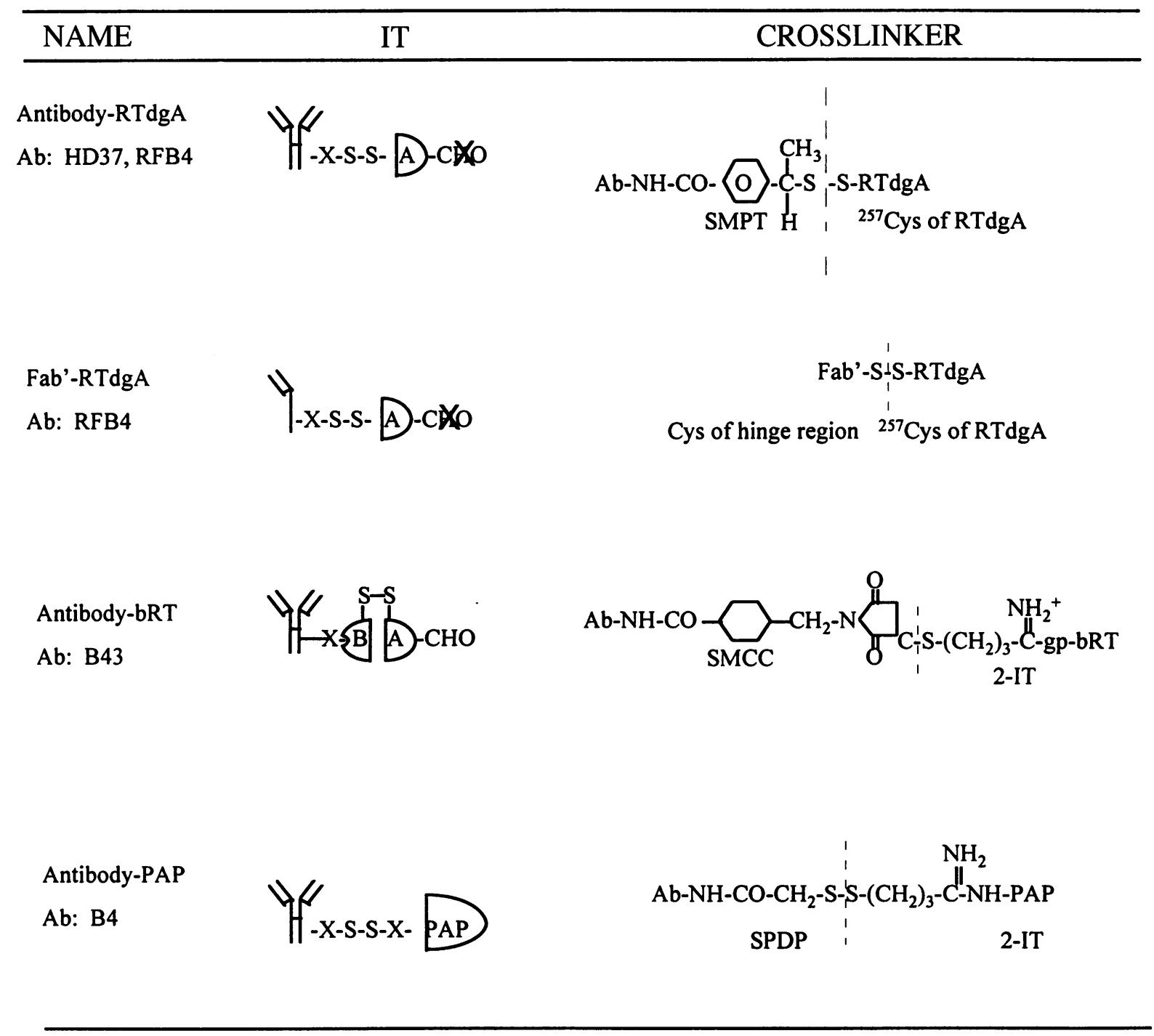

FIG. 1. Structure of immunotoxins used in the treatment of lymphomas

Antibodies HD37, B43, and B4 are murine monoclonals anti-CD19. Antibody RFB4 is a murine monoclonal antiCD22. Abbreviations: A, ricin A chain; Ab, antibody; B, ricin B chain; CHO, carbohydrate moiety; gp, glycopeptide derived from fetuin; 2-IT, 2-imminothiolane; S-S, disulfide bond; X, cross-linking bridge.

protein synthesis in targeted cells by removing a specific adenine from the ribosomal RNA (17). The RFB4 anti-CD22 and HD37 anti-CD19 do not recognize cells other than B cells. The RFB4 and HD37 MAbs conjugated to dgRTA kill human neoplastic B cells that express the relevant markers. When Daudi cells are used as targets, RFB4-IgG-dgRTA has an $\mathrm{IC}_{50}$ of $10^{-12} \mathrm{M}$ (13) and is therefore approximately 10 -fold more potent than its $\mathrm{Fab}^{\prime}$ fragment conjugated to the same toxin $\left(\mathrm{IC}_{50}=10^{-11} \mathrm{M}\right)(14)$. In contrast, the HD37-IgG-RTA has an $\mathrm{IC}_{50}$ of $1-5 \times 10^{-11} \mathrm{M}$ (13) and is 10- to 50-fold less cytotoxic than RFB4-IgG-dgRTA. Recombinant RTA (rRTA), lacking all carbohydrates, may also be used for chemical construction of ITs (18-20).

\section{Blocked Ricin (bRT)-Containing ITs}

The anti-CD19 monoclonal antibody B4 has been conjugated to bRT. The bRT is prepared by chemically blocking the galactose-binding sites on the ricin toxin B chain (RTB) with ligands containing $\mathrm{N}$-linked oligosaccharides derived from fetuin $(5-8,21)$. The MAb is treated with the SMCC cross-linker to establish a thioether bond between the MAb and the galactose-containing oligosaccharide provided with a sulfhy- 
dryl group by treatment with 2-iminothiolane $(6,21)$. The bRT-containing IT molecule is unable to bind to cells other than target cells (22). The in vitro cytotoxicity of B4-bRT has been tested on $\mathrm{CD} 19^{+}$human Burkitt's lymphoma cell lines, where it was found to be 5 -fold more potent than the HD37-dgRTA (4).

\section{PAP-Containing ITs}

The anti-CD19 murine monoclonal antibody B43 has been conjugated to PAP following derivatization with the $N$-succinimidyl-3-(2-pyridyldithiol)propionate (SPDP) cross-linker and 2-iminothiokene-treated PAP (23). Its in vitro cytotoxicity on Nalm-6 cells was relatively low with an $\mathrm{IC}_{50}$ approaching $10^{-9} \mathrm{M}(9,23)$. It is therefore 50 - to 100-fold weaker than HD37dgRTA and 1,000-fold weaker than the B4-BRT conjugate. Nevertheless, the B43 PAP has good activity in vivo (24).

\section{TREATMENT OF MICE WITH HUMAN LYMPHOMAS (TABLE 1)}

\section{Animal Models}

Human xenografts have been successfully grown in immunodeficient mice lacking $\mathrm{T}$ cells (Nude mice) or both $\mathrm{T}$ and $\mathrm{B}$ cells (SCID mice). Lymphoma cells are injected either subcutaneously, where they grow as solid tumors (25), or intravenously, where they grow in a disseminated fashion more akin to human lymphomas (26). Disseminated tumors are present in the lung, kidney, ovary, liver, spleen, and the vertebral column of the mice. The growth of disseminated tumor in the spinal canal causes paralysis of the animal shortly prior to death. Both survival and mean paralysis time (MPT), which is predictive of death, have been used as end points in this animal model $(26,27)$.

\section{Treatment of Xenografted Mice}

Xenografted mice are treated in one of two ways. For minimal residual disease (MRD), the mice are inoculated with tumor cells approximately $24 \mathrm{hr}$ prior to commencing therapy. For more advanced disease, mice that would normally survive for 30-50 days following inoculation with tumor cells are treated 7-21 days after tumor cell inoculation. In mice with solid subcutaneous tumors, ITs are administered when the tumor has a measurable diameter of $1 \mathrm{~cm}$ or less.

\section{Therapeutic Effects of ITs}

Single ITs or mixtures of ITs have also been administered to tumor-bearing mice alone or in conjunction with chemotherapy $(20,25,28-36)$. ITs prepared with either anti-CD 22 or anti-CD 19 and any one of the three toxins mentioned above have significant antitumor activity. In general, a combination of the two ITs exerts the best effect (29). Although therapy with ITs alone can be highly effective, it is rarely curative in all animals, even when administered shortly after injection with tumor cells. However, when ITs are combined with chemotherapy in early disease, the effects are curative. In more advanced disease, ITs have significant antitumor activity but are not curative even when administered with chemotherapy. Interestingly, in advanced disease, ITs administered before or during chemotherapy are more therapeutic than when they are given after chemotherapy (31). This suggests that the IT may sensitize the tumor to chemotherapeutic agents. Taken together, the mouse studies have demonstrated that ITs will probably work best in the setting of MRD, possibly when administered before or in conjunction with chemotherapy.

\section{THERAPY OF LYMPHOMA PATIENTS (TABLE 2)}

Although studies in mice suggest that ITs should be administered as cocktails along with chemotherapy in the setting of MRD, it is not possible to do this in humans until Phase I safety criteria are established. Therefore, to date, virtually all patients treated with ITs have been end-stage multiply relapsed patients often with bulky disease. Because of this, it has not yet been possible to determine how effectively ITs will work in an optimal setting. However, a number of Phase I trials have clearly defined the side effects, safe dosages, and pharmacokinetics of these targeted therapies in humans and have indicated that the ITs do indeed have antitumor activity in humans (37-43).

\section{dgRTA ITs}

The three dgRTA-based ITs that have been used in Phase I trials are the Fab'-RFB4-dgRTA, the IgG-RFB4-dgRTA, and the HD37-dgRTA. The ITs have been administered either by continuous infusion (c.i.) over 8 days or $24 \mathrm{hr}$ or by bolus infusion (b.i.) every other day for a total of four 


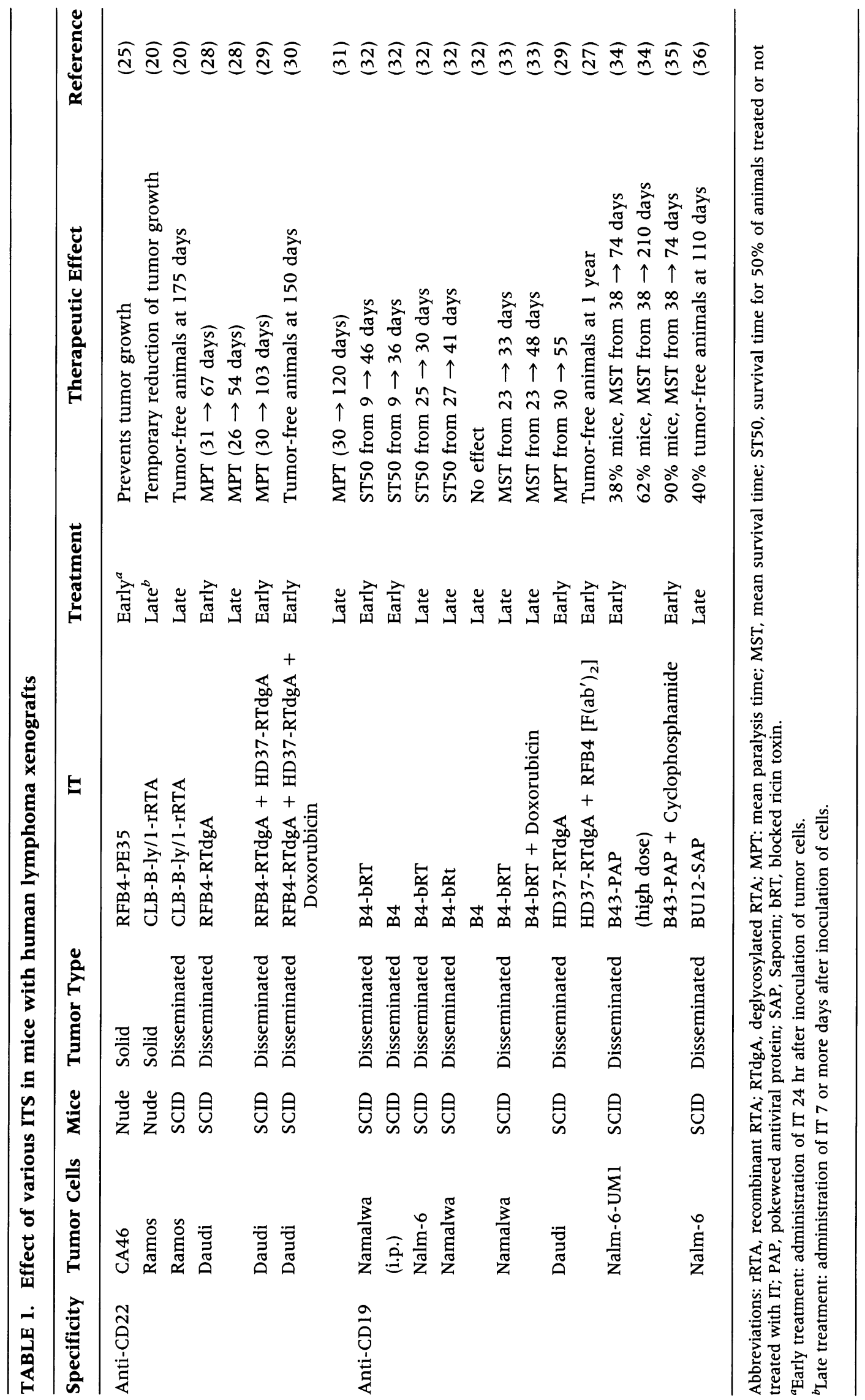




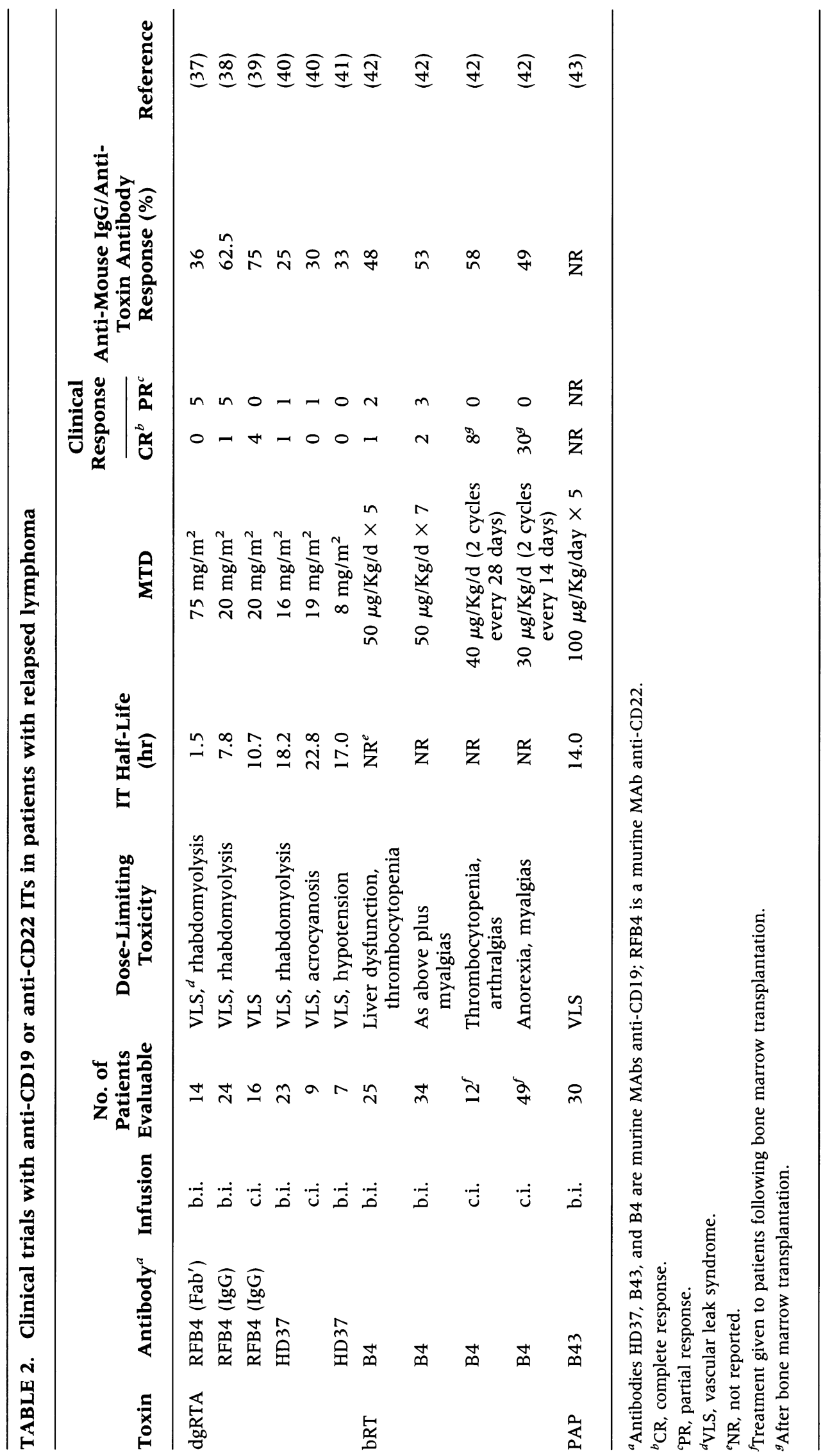


doses (37-41). In addition, a combination of the two ITs have been given by c.i. over 8 days. The following can be concluded from the Phase I trials: (1) The maximum tolerated dose (MTDs) ranges from 15 to $30 \mathrm{mg} / \mathrm{m}^{2}(600-900 \mu \mathrm{g} / \mathrm{kg})$, depending on the dose regimen. In general, the MTD is slightly lower for the c.i. regimen than for the b.i. regimen and higher for patients with circulating tumor cells using either regimen. (2) Side effects include manifestations of vascular leak syndrome (VLS) as well as myalgias. In most patients, these side effects are reversible following the completion of therapy. (3) About onethird of the patients make anti-IT antibodies after a single course of IT and up to $40-50 \%$ make antibodies after four or more courses. Antibody responses are often low and take 30-60 days to develop after therapy. Nevertheless, in patients who do not make antibodies, up to five or six courses can be given. (4) Clinical responses are observed in $15-40 \%$ of the patients and generally are best in those patients with the smallest tumor burdens. Given the results of the Phase I trials, the strategy for Phase II and III trials includes the administration of a mixture of the two ITs by b.i. at a dose of approximately 10-15 $\mathrm{mg} / \mathrm{m}^{2}$. If the response rate in the Phase II trials is good, Phase III trials will determine whether ITs can indeed be of benefit to patients with NHL.

\section{bRT-based ITs}

The B4-bRT IT has been evaluated in Phase I and II trials (42) and is now being studied in a large Phase III trial. When administered either daily by a 1-hr infusion for 5 consecutive days or continuously over 7 days to patients with B lymphoma, the MTDs were 250 and $350 \mu \mathrm{g} / \mathrm{Kg}$, respectively. The side effects consisted of transient hepatotoxicity and thrombocytopenia. The complete responses (CRs) were of brief duration because of the small doses delivered to patients with large tumor burdens. To use the IT in a more desirable setting, it has now been administered as adjuvant therapy in patients with relapsed NHL following autologous bone marrow transplantation. No new toxicities were observed with one or more courses of therapy and only 2 of 38 patients developed thrombocytopenia. Thirty patients remain in CR for a median follow-up of 15 months.

A Phase III clinical trial is ongoing in patients who achieve $C R$ after bone marrow transplantation. To date, the patients have received two courses of B4-bRT IT or no further therapy.

\section{PAP-based ITs}

The B43-PAP IT has been evaluated in a Phase I dose-escalation trial to 30 patients with leukemia (43). The dose level ranged from $0.1 \mu \mathrm{g}$ to $250 \mu \mathrm{g} / \mathrm{Kg} /$ day for 5 consecutive days and $100 \mu \mathrm{g} / \mathrm{Kg} /$ day $\times 5$ has been identified as the safe dosage level for further studies. A total of 16 patients were treated with this dosage. Vascular leak with high serum creatine and bilirubin was observed. Clinical responses were not reported but it was found that the anti-leukemic response was greater in patients with greater systemic exposure to IT and a lower peripheral blast count.

\section{FUTURE PERSPECTIVES}

The development of ITs is a lengthy and complex process and the optimization of ITs for cancer therapy is even more complex, but there is every reason to believe that success for at least some tumors will be achieved in the next 5 to 10 years. In fact, for the therapy of cancer, ITs have yielded higher response rates in Phase I/II trials than have some of the drugs used today (when tested in similar trials). The generation of new constructs, combinatorial therapy, and, in the case of cancer therapy, treatment of tumors that are amenable to IT-mediated killing (e.g., MRD) should eventually result in effective treatment protocols.

\section{ACKNOWLEDGMENTS}

This work was supported by grants from the National Institutes of Health (CA28149), the Texas Higher Education Coordinating Board (003644-150), and The Meadows Foundation.

\section{REFERENCES}

1. Harris NL, Jaffe ES, Stein H, et al. (1994) A revised European-American classification of lymphoid neoplasms: A proposal from the International Lymphoma Study Group. Blood 84: 1361-1392.

2. Rosenberg SA. (1994) Classification of lymphoid neoplasms. Blood 84: 1359-1363.

3. Hiddemann $\mathrm{W}$, Longo DL, Coiffier $\mathrm{B}$, et al. (1996) Lymphoma classification-The gap between biology and clinical management is closing. Blood 88: 4085-4089.

4. Lambert JM, Goldmacher VS, Collinson AR, Nadler LM, Blattler WA. (1991) An immu- 
notoxin prepared with blocked ricin: A natural plant toxin adapted for therapeutic use. Cancer Res. 51: 6236-6242.

5. Thorpe PE, Detre SI, Foxwell BMJ, et al. (1985) Modification of the carbohydrate in ricin with metaperiodate-cyanoborohydride mixtures. Effects on toxicity and in vivo distribution. Eur. J. Biochem. 147: 197-206.

6. Thorpe PE, Wallace PM, Knowles PP, et al. (1988) Improved anti-tumor effects of immunotoxins prepared with deglycosylated ricin A chain and hindered disulfide linkages. Cancer Res. 48: 6396-6403.

7. Ghetie M, May RD, Till M, et al. (1988) Evaluation of ricin A chain-containing immunotoxins directed against $\mathrm{CD} 19$ and CD22 antigens on normal and malignant human B-cells as potential reagents for in vivo therapy. Cancer Res. 48: 2610-2617.

8. Shen G, Li J, Ghetie M, et al. (1988) Evaluation of four CD22 antibodies as ricin A chain-containing immunotoxins for the in vivo therapy of human B-cell leukemias and lymphomas. Int. J. Cancer 42: 792-797.

9. Irvin JD, Uckun FM. (1992) Pokeweed antiviral protein-ribosome inactivation and therapeutic applications. Pharmacol. Ther. 55: 279-302.

10. Anderson KC, Bates MP, Slaughenhoupt BL, Pinkus GS, Schlossman SF, Nadler LM. (1984) Expression of human B cell-associated antigens on leukemias and lymphomas: A model of human B cell differentiation. Blood 63: 1424-1433.

11. Campana D, Janossy G, Bofill $M$, et al. (1985) Human B cell development. I. Phenotypic differences of B lymphocytes in the bone marrow and peripheral lymphoid tissue. J. Immunol. 134: 1524-1529.

12. Dörken B, Moldenhauer G, Schwartz R, Pezzutto A, Hammerling G. (1983) B cell differentiation antigens identified by monoclonal antibodies (HD6, HD28, HD37, HD39). Immunobiology 165: 253-254.

13. Ghetie V, Thorpe PE, Ghetie M, Knowles P, Uhr JW, Vitetta ES. (1991) The GLP large scale preparation of immunotoxins containing deglycosylated ricin A chain and a hindered disulfide bond. J. Immunol. Methods 142: 223-230.

14. Ghetie V, Ghetie M, Uhr JW, Vitetta ES. (1988) Large scale preparation of immunotoxins constructed with the Fab' fragment of IgGl murine monoclonal antibodies and chemically deglycosylated ricin A chain. J. Immunol. Methods 112: 267-277.

15. Fulton RJ, Blakey DC, Knowles PP, Uhr JW, Thorpe PE, Vitetta ES. (1986) Production of ricin $A_{1}, A_{2}$, and $B$ chains and characterization of their toxicity. J. Biol. Chem. 261: 5314-5319.

16. Knowles PP, Thorpe PE. (1987) Purification of immunotoxins containing ricin A-chain and abrin A-chain using Blue Sepharose CL6B. Anal. Biochem. 160: 440-443.

17. Endo Y, Mitsui K, Motizuki M, Tsurugi K. (1987) The mechanism of action of ricin and related toxic lectins on eukaryotic ribosomes. The site and the characteristics of the modification in $28 \mathrm{~S}$ ribosomal RNA caused by the toxins. J. Biol. Chem. 262: 5908-5912.

18. Bjorn MJ, Ring D, Frankel A. (1985) Evaluation of monoclonal antibodies for the development of breast cancer immunotoxins. Cancer Res. 45: 1214-1221.

19. Weiner LM, O'Dwyer J, Kitson J, et al. (1989) Phase I evaluation of an anti-breast carcinoma monoclonal antibody 260F9-recombinant ricin A chain immunoconjugate. Cancer Res. 49: 4062-4067.

20. Vanhorssen PJ, Preijers FWMB, Vanoosterhout YVJM, Dewitte T. (1996) Highly potent CD22-recombinant ricin A results in complete cure of disseminated malignant B-cell xenografts in SCID mice but fails to cure solid xenografts in Nude mice. Int. J. Cancer 68: $378-383$.

21. Blakely DC, Watson GJ, Knowles PP, Thorpe PE. (1987) Effect of chemical deglycosylation of ricin A chain on the in vivo fate and cytotoxic activity of an immunotoxin composed of ricin A chain and anti-Thy 1.1 antibody. Cancer Res. 47: 947-952.

22. Nadler LM, Anderson KC, Marti G, et al. (1983) B4, a human B lymphocyte-associated antigen expressed on normal, mitogenactivated, and malignant $\mathrm{B}$ lymphocytes. J. Immunol. 131: 244-250.

23. Myers DE, Irvin JD, Smith RS, Kuebelbeck VM, Uckun FM. (1991) Production of a pokeweed antiviral protein (PAP)-containing immunotoxin, B43-PAP, directed against the CD19 human B lineage lymphoid differentiation antigen in highly purified form for human clinical trials. J. Immunol. Methods 136: 221-237.

24. Uckun FM. (1993) Immunotoxins for the treatment of leukemia. Br. J. Haematol. 85: 435-438. 
25. Mansfield E, Pastan I, FitzGerald DJ. (1996) Characterization of RFB4-Pseudomonas exotoxin A immunotoxins targeted to $\mathrm{CD} 22$ on B-cell malignancies. Bioconjug. Chem. 7: 557563.

26. Ghetie MA, Richardson J, Tucker T, Jones D, Uhr JW, Vitetta ES. (1990) Disseminated or localized growth of a human B-cell tumor (Daudi) in SCID mice. Int. J. Cancer 45: 481485.

27. Ghetie MA, Picker LJ, Richardson JA, Tucker K, Uhr JW, Vitetta ES. (1994) Anti-CD19 inhibits the growth of human B-cell tumor lines in vitro and of Daudi cells in SCID mice by inducing cell cycle arrest. Blood 83: 13291336.

28. Ghetie MA, Richardson J, Tucker T, Jones D, Uhr JW, Vitetta ES. (1991) Antitumor activity of $\mathrm{Fab}^{\prime}$ and IgG-anti-CD22 immunotoxins in disseminated human B lymphomas grown in mice with severe combined immunodeficiency disease: Effect on tumor cells in extranodal sites. Cancer Res. 51: 5876-5880.

29. Ghetie MA, Tucker K, Richardson J, Uhr JW, Vitetta ES. (1992) The antitumor activity of an anti-CD22 immunotoxin in SCID mice with disseminated Daudi lymphoma is enhanced by either an anti-CD19 antibody or an anti-CD 19 immunotoxin. Blood 80: 23152320.

30. Ghetie M-A, Tucker K, Richardson J, Uhr JW, Vitetta ES. (1994) Eradication of minimal disease in severe combined immunodeficient mice with disseminated Daudi lymphoma using chemotherapy and an immunotoxin cocktail. Blood 84: 702-707.

31. Ghetie MA, Podar EM, Gordon BE, Pantazis P, Uhr JW, Vitetta ES. (1996) Combination immunotoxin treatment and chemotherapy in SCID mice with advanced, disseminated Daudi lymphoma. Int. J. Cancer 67: 1-4.

32. Shah SA, Halloran PM, Ferris CA, et al. (1993) Anti-B4-blocked ricin immunotoxin shows therapeutic efficacy in four different SCID mouse tumor models. Cancer Res. 53: 1360-1367.

33. O'Connor R, Liu C, Ferris CA, et al. (1995) Anti-B4-blocked ricin synergizes with doxorubicin and etoposide on multidrug-resistant and drug-sensitive tumors. Blood 86: 42864294.
34. Uckun FM, Finnegan D, Gunther R, et al. (1994) In vivo efficacy of B-43 (anti-CD 19)pokeweed antiviral protein (PAP) immunotoxin against BCL-1 murine B-cell leukemia. Blood 84: 702-707.

35. Uckun FM, Chelstrom LM, Finnegan D, et al. (1993) Effective immunochemotherapy of $\mathrm{CALLA}^{+} \mathrm{C}^{+}$human pre-B acute lymphoblastic leukemia in mice with severe combined immunodeficiency using B43 (anti-CD 19) pokeweed antiviral protein immunotoxin plus cyclophosphamide. Blood 79: 3116-3129.

36. Flavell DJ, Flavell SU, Boehm DA, et al. (1995) Preclinical studies with the anti-CD19-saporin immunotoxin BU12-SAPORIN for the treatment of human-B-cell tumours. Br. J. Cancer 72: 1373-1379.

37. Vitetta ES, Stone $M$, Amlot $P$, et al. (1991) Phase I immunotoxin trial in patients with B-cell lymphoma. Cancer Res. 51: 4052-4058.

38. Amlot PL, Stone MJ, Cunningham D, et al. (1993) A phase I study of an anti-CD22deglycosylated ricin $A$ chain immunotoxin in the treatment of B-cell lymphomas resistant to conventional therapy. Blood 82: 2624-2633.

39. Sausville EA, Headlee D, Stetler-Stevenson $M$, et al. (1995) Continuous infusion of the anti-CD22 immunotoxin IgG-RFB4-SMPTdgA in patients with B-cell lymphoma: A phase I study. Blood 85: 3457-3465.

40. Stone MJ, Sausville EA, Fay JW, et al. (1996) A Phase I study of bolus versus continuous infusion of the anti-CD19 immunotoxin, IgG-HD37-dgA, in patients with B-cell lymphoma. Blood 88: 1188-1197.

41. Conry RM, Khazaeli MB, Saleh MN, et al. (1995) Phase I trial of an anti-CD19 deglycosylated ricin $\mathrm{A}$ chain immunotoxin in non-Hodgkin's lymphoma: Effect of an intensive schedule of administration. J. Immunother. 18: 231-241.

42. Kwak LW, Grossbard ML, Urba WJ. (1995) Clinical applications of monoclonal antibodies in cancer. In: De Vita VT, Jr, Hellman S, Rosenberg SA (eds). Biologic Therapy of Cancer, J.B. Lippincott, Philadelphia, pp. 553-565.

43. Uckun FM. (1995) B43-pokeweed antiviral protein (B43-PAP) immunotoxin [abstract]. Fourth International Symposium on Immunotoxins, Myrtle Beach, S. Carolina, p. 162. 